\title{
Fabrication of Ionic Liquid-based Pickering Emulsion and Its Enhancement for Tri-isobutene Formation in Isobutene Oligomerization
}

\author{
Lunchao Lv ${ }^{\dagger, \ddagger}$, Hongyan Wang ${ }^{\ddagger}$, Jian Chen ${ }^{\ddagger}$, , Yingying Cao ${ }^{\ddagger}$, , Hui Wang $^{\ddagger,},{ }^{*}$, \\ Baozeng Ren ${ }^{\dagger}, *$, Suojiang Zhang $\$,,^{*}$ \\ ${ }^{\dagger}$ School of Chemical Engineering, Zhengzhou University, Zhengzhou, 450001 P.R. China \\ *Beijing Key Laboratory of Ionic Liquids Clean Process, CAS Key Laboratory of Green Process \\ and Engineering, State Key Laboratory of Multiphase Complex Systems, Institute of Process \\ Engineering, Chinese Academy of Sciences, Beijing, 100190 P.R. China, Innovation Academy for \\ Green Manufacture, Chinese Academy of Sciences \\ §University of Chinese Academy of Sciences, Beijing, 100049 P.R. China \\ *Corresponding authors: E-mail addresses: huiwang@ipe.ac.cn (H. Wang), renbz@zzu.edu.cn (B. \\ Ren), sjzhang@ipe.ac.cn (S. Zhang), Fax: 861082627080.
}




\section{EDS analysis of the emulsifiers}

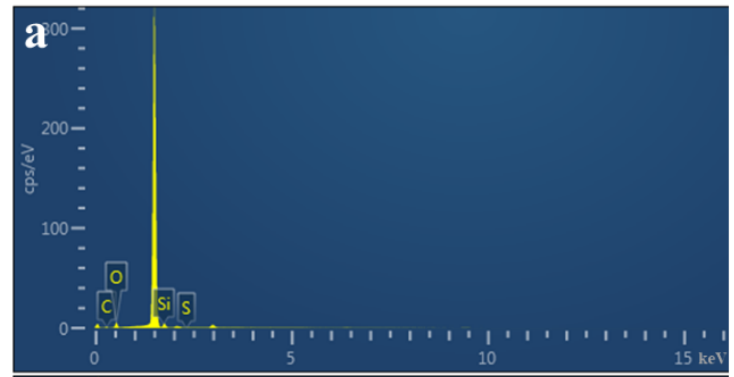

\begin{tabular}{|c|c|c|}
\hline Element & $\mathrm{wt} \%$ & Atomic (\%) \\
\hline $\mathrm{C}$ & 31.02 & 39.42 \\
\hline $\mathrm{O}$ & 56.26 & 53.67 \\
\hline $\mathrm{Si}$ & 12.64 & 6.87 \\
\hline $\mathrm{S}$ & 0.08 & 0.04 \\
\hline Total: & 100.00 & 100.00 \\
\hline
\end{tabular}

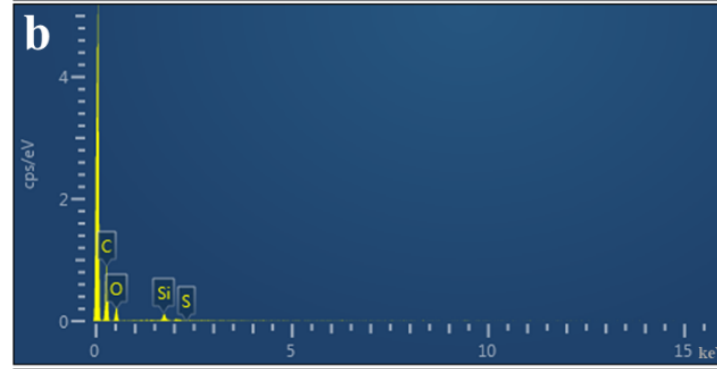

\begin{tabular}{|c|c|c|}
\hline Element & $\mathrm{wt} \%$ & Atomic (\%) \\
\hline $\mathrm{C}$ & 68.95 & 75.06 \\
\hline $\mathrm{O}$ & 29.84 & 24.38 \\
\hline $\mathrm{Si}$ & 1.21 & 0.56 \\
\hline $\mathrm{S}$ & 0.00 & 0.00 \\
\hline Total: & 100.00 & 100.00 \\
\hline
\end{tabular}

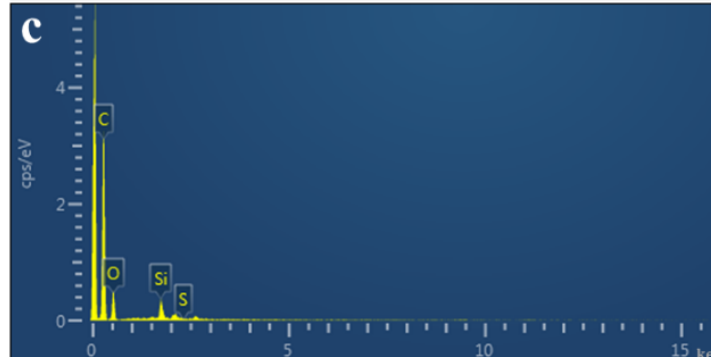

\begin{tabular}{|c|c|c|}
\hline Element & $\mathrm{wt} \%$ & Atomic (\%) \\
\hline $\mathrm{C}$ & 75.84 & 81.02 \\
\hline $\mathrm{O}$ & 23.00 & 18.45 \\
\hline $\mathrm{Si}$ & 1.16 & 0.53 \\
\hline $\mathrm{S}$ & 0.00 & 0.00 \\
\hline Total: & 100.00 & 100.00 \\
\hline
\end{tabular}

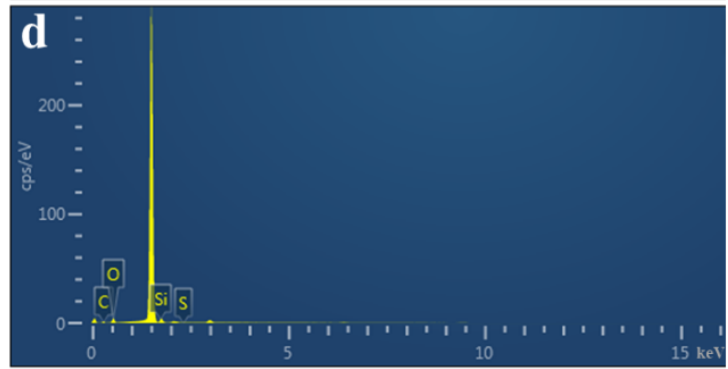

\begin{tabular}{|c|c|c|}
\hline Element & $\mathrm{wt} \%$ & Atomic (\%) \\
\hline $\mathrm{C}$ & 34.97 & 43.88 \\
\hline $\mathrm{O}$ & 52.43 & 49.38 \\
\hline $\mathrm{Si}$ & 12.38 & 6.64 \\
\hline $\mathrm{S}$ & 0.21 & 0.10 \\
\hline Total: & 100.00 & 100.00 \\
\hline
\end{tabular}

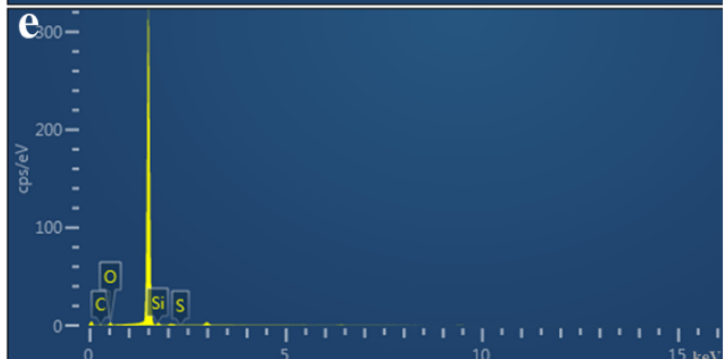

\begin{tabular}{|c|c|c|}
\hline Element & $\mathrm{wt} \%$ & Atomic (\%) \\
\hline $\mathrm{C}$ & 32.77 & 41.58 \\
\hline $\mathrm{O}$ & 53.61 & 51.06 \\
\hline $\mathrm{Si}$ & 13.22 & 7.17 \\
\hline $\mathrm{S}$ & 0.40 & 0.19 \\
\hline Total: & 100.00 & 100.00 \\
\hline
\end{tabular}

Figure S1. EDS spectra and C, O, Si, S element contents of the silica based nanoparticles: (a) $\mathrm{SiO}_{2}$, (b) $\mathrm{C}_{1}-\mathrm{SiO}_{2}-\mathrm{C}_{1}$, (c) $\mathrm{C}_{8}-\mathrm{SiO}_{2}$, (d) $\mathrm{C}_{8}-\mathrm{SiO}_{2}-\mathrm{SO}_{3} \mathrm{H}$, (e) $\mathrm{C}_{18}-\mathrm{SiO}_{2}-\mathrm{SO}_{3} \mathrm{H}$. 
2. Contact angle analysis

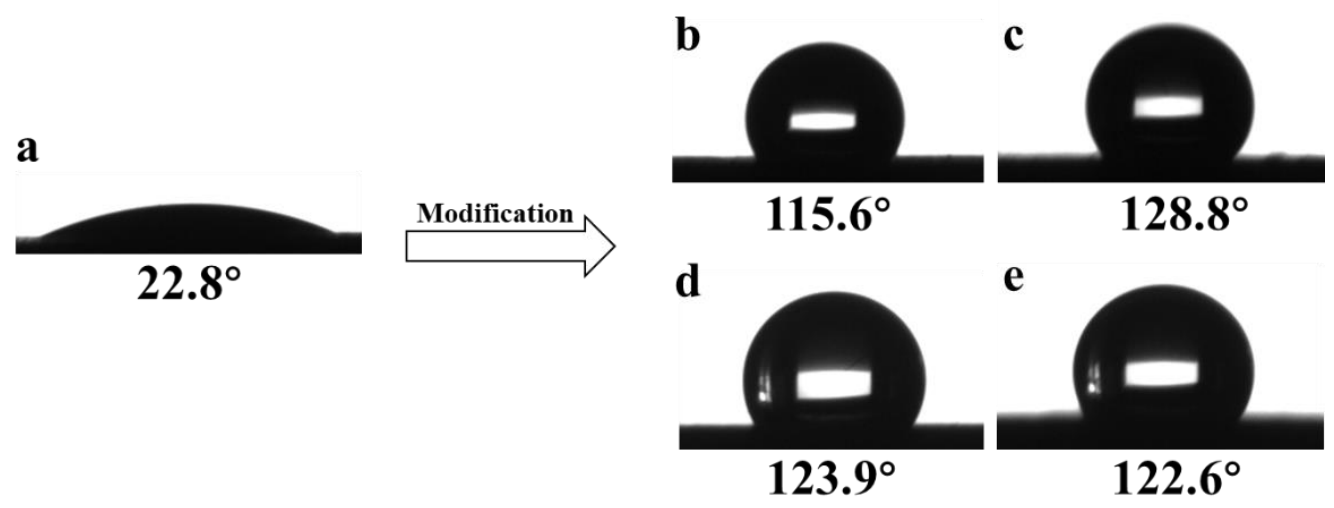

Figure S2. Contact angles of unmodified silica (a), $\mathrm{C}_{1}-\mathrm{SiO}_{2}-\mathrm{C}_{1}$ (b), $\mathrm{C}_{8}-\mathrm{SiO}_{2}(\mathrm{c}), \mathrm{C}_{8}-\mathrm{SiO}_{2}-\mathrm{SO}_{3} \mathrm{H}(\mathrm{d})$, and $\mathrm{C}_{18}-\mathrm{SiO}_{2}-\mathrm{SO}_{3} \mathrm{H}(\mathrm{e})$. 
3. Macro and micro analysis of the emulsions fabricated by different emulsifiers
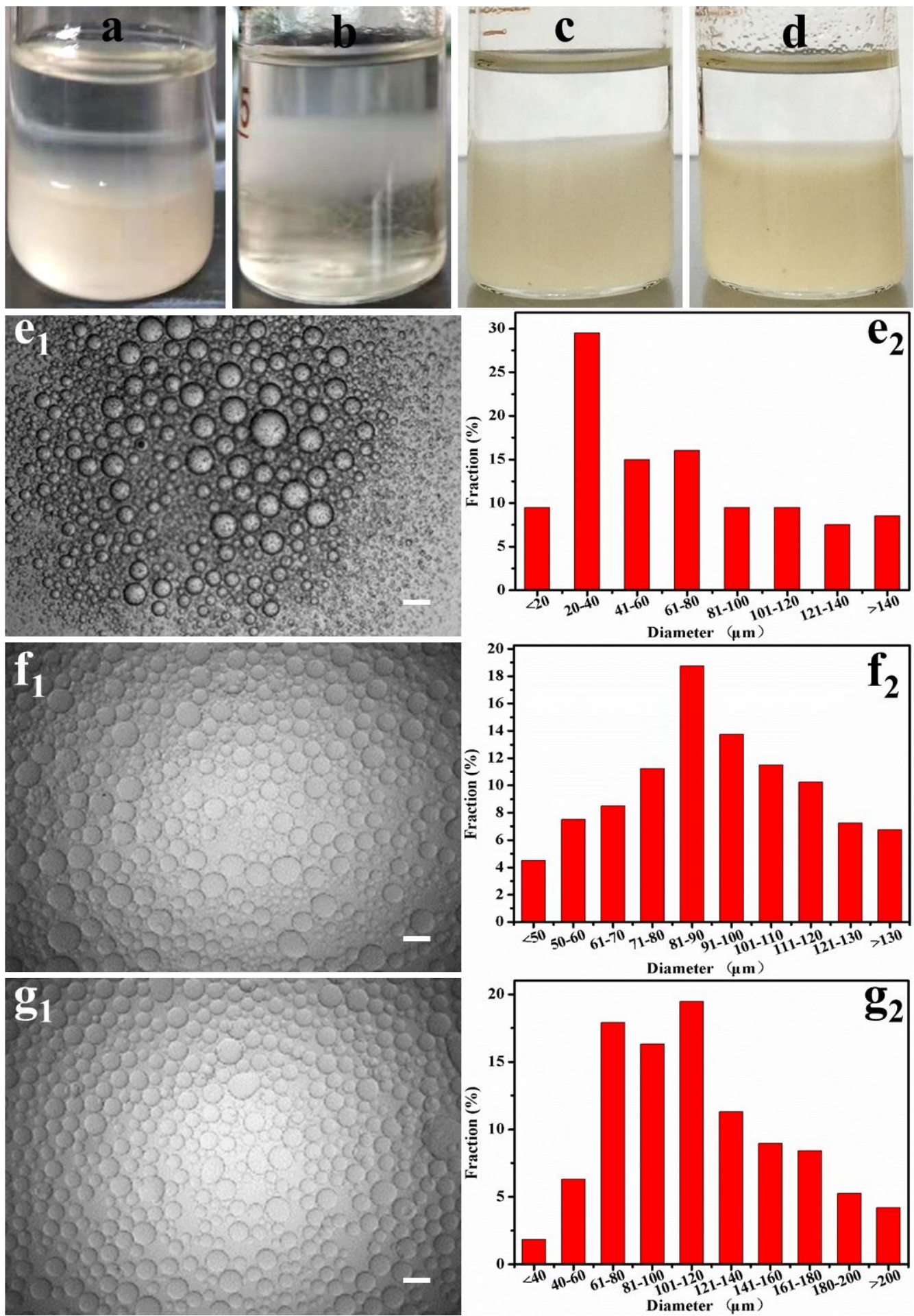

Figure S3. Photos of the emulsions constructed by (a) $\mathrm{C}_{1}-\mathrm{SiO}_{2}-\mathrm{C}_{1}$, (b) $\mathrm{C}_{8}-\mathrm{SiO}_{2}$, (c) $\mathrm{C}_{8}-\mathrm{SiO}_{2}-\mathrm{SO}_{3} \mathrm{H}$ and (d) $\mathrm{C}_{18}-\mathrm{SiO}_{2}-\mathrm{SO}_{3} \mathrm{H}$; Micrographs and droplet size distributions of the emulsions constructed by $\mathrm{C}_{1}-\mathrm{SiO}_{2}-\mathrm{C}_{1}\left(\mathrm{e}_{1}\right.$ and $\left.\mathrm{e}_{2}\right), \mathrm{C}_{8}-\mathrm{SiO}_{2}-\mathrm{SO}_{3} \mathrm{H}\left(\mathrm{f}_{1}\right.$ and $\left.\mathrm{f}_{2}\right), \mathrm{C}_{18}-\mathrm{SiO}_{2}-\mathrm{SO}_{3} \mathrm{H}\left(\mathrm{g}_{1}\right.$ and $\left.\mathrm{g}_{2}\right)$; Scale bar: $200 \mu \mathrm{m}$. Note: the ionic liquid content was $20 \%$ based on the mass of the aqueous phase. 


\section{Stability of the functionalized silica in $\mathrm{IL}_{2} \mathrm{H}_{2} \mathrm{SO}_{4}$}

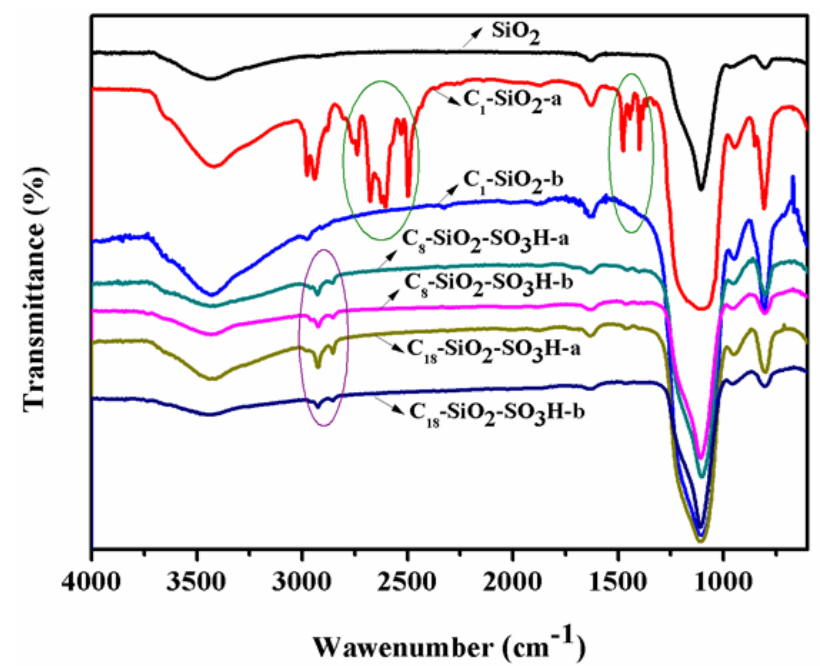

Figure S4. FTIR spectra of $\mathrm{SiO}_{2}$ and modified silica nanoparticles. Note: "a" represents the spectra of the freshly modified silica and " $b$ " represents the spectra of the recovered modified silica after the emulsion was constructed. 
5. Photos of the emulsions containing ionic liquid of various concentrations

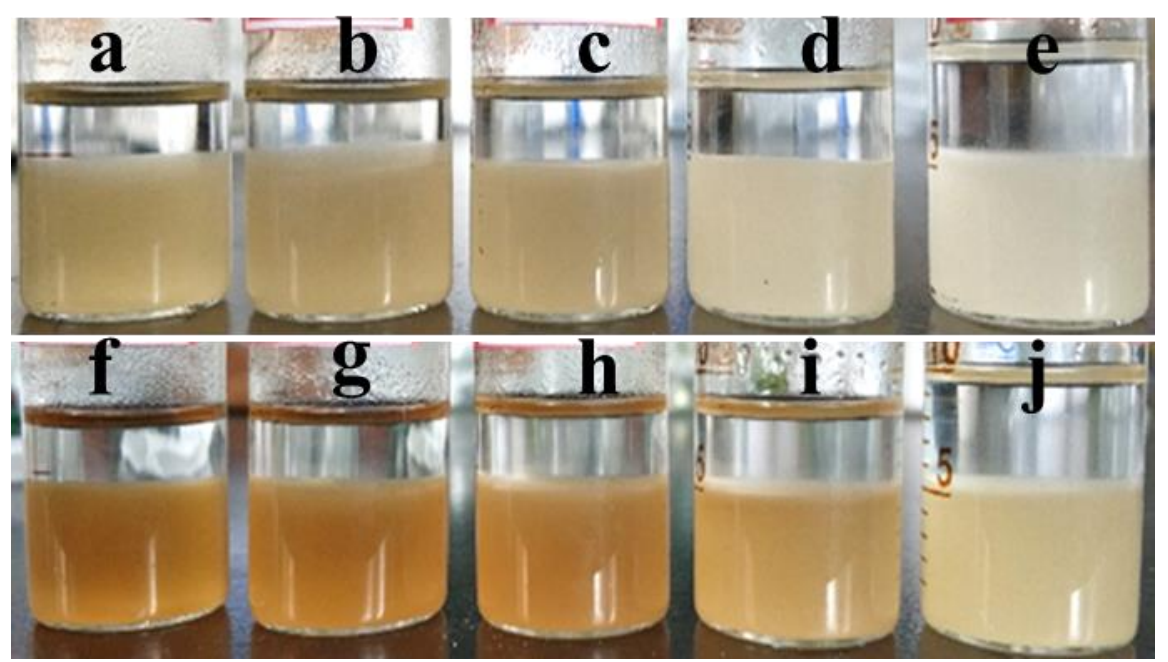

Figure S5. Photos of the emulsions constructed by $\mathrm{C}_{8}-\mathrm{SiO}_{2}-\mathrm{SO}_{3} \mathrm{H}$ with the ionic liquid concentrations in the acid phase of: (a) $0 \%$, (b) $10 \%$, (c) $20 \%$, (d) $40 \%$, (e) $60 \%$; Photos of the emulsions constructed by $\mathrm{C}_{18}-\mathrm{SiO}_{2}-\mathrm{SO}_{3} \mathrm{H}$ with the ionic liquid concentrations in the acid phase of: (f) $0 \%$, (g) $10 \%$, (h) $20 \%$, (i) $40 \%$, (j) $60 \%$. 


\section{Effect of ionic liquid concentration on emulsion droplet size}

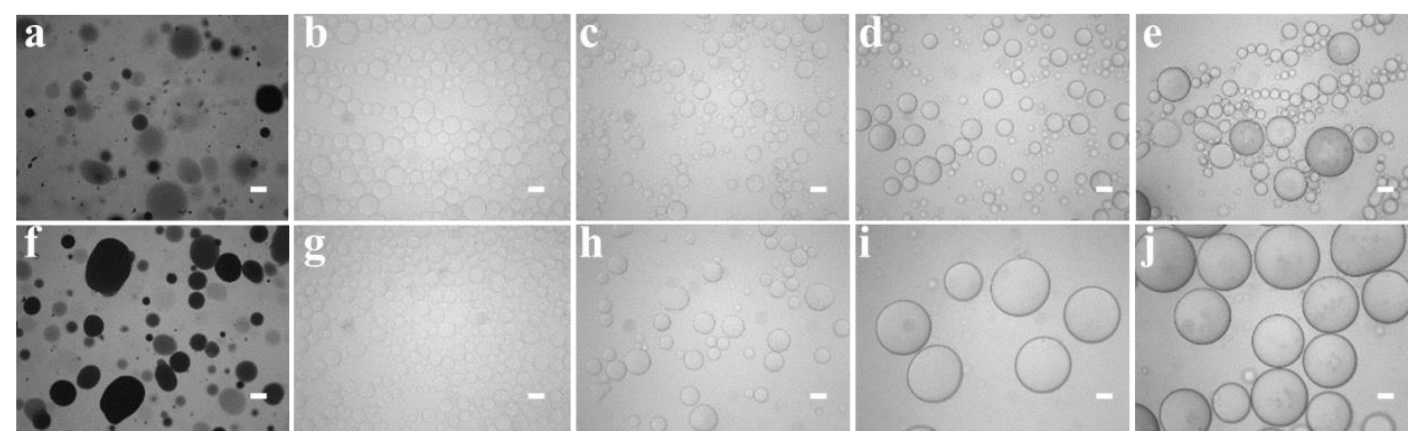

Figure S6. Micrographs of the emulsions constructed by $\mathrm{C}_{8}-\mathrm{SiO}_{2}-\mathrm{SO}_{3} \mathrm{H}$ using different concentrations of IL in the acid phase: (a) $0 \%$, (b) $10 \%$, (c) $20 \%$, (d) $40 \%$, (e) $60 \%$; Micrographs of the emulsions constructed by $\mathrm{C}_{18}-\mathrm{SiO}_{2}-\mathrm{SO}_{3} \mathrm{H}$ with various IL concentrations: (f) $0 \%$, (g) $10 \%$, (h) $20 \%$, (i) $40 \%$, (j) $60 \%$. Note: Due to the low refractive index in the system containing no IL, the droplet profile can only be observed by adding methyl orange (a and f). Scale bar: $200 \mu \mathrm{m}$. 
7. Photos of the emulsions stored for different time intervals

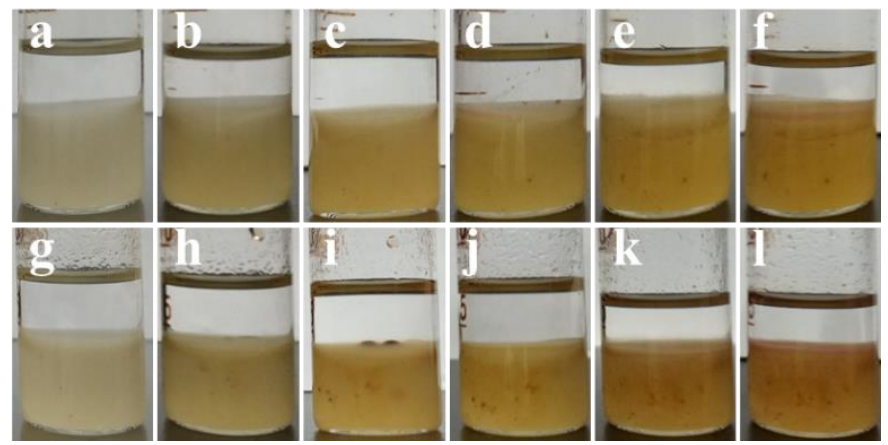

Figure S7. Emulsions constructed by $2 \% \mathrm{C}_{8}-\mathrm{SiO}_{2}-\mathrm{SO}_{3} \mathrm{H}$ stored for different time intervals: (a) $0 \mathrm{~h}$, (b) $5 \mathrm{~h}$, , (c) $15 \mathrm{~h}$, (d) $24 \mathrm{~h}$, (e) $48 \mathrm{~h}$, (f) $72 \mathrm{~h}$; Emulsions constructed by $2 \% \mathrm{C}_{18}-\mathrm{SiO}_{2}-\mathrm{SO}_{3} \mathrm{H}$ stored for different time intervals: (g) 0 h, (h) $5 \mathrm{~h}$, (i) $15 \mathrm{~h}$, (j) 24 h, (k) 48 h, (l) $72 \mathrm{~h}$. 
8. Photos of the emulsions stored at different temperatures

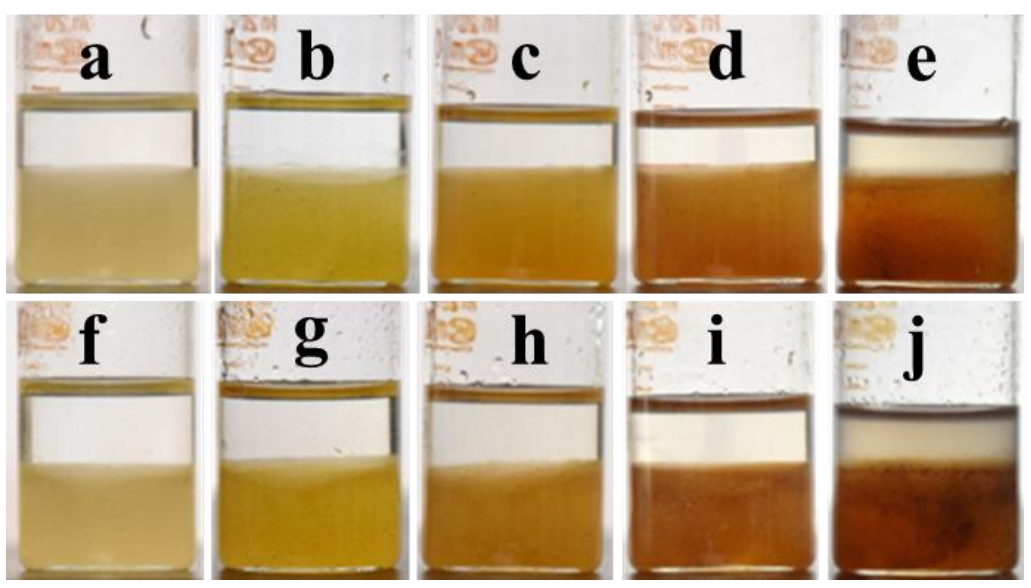

Figure S8. Emulsions constructed by $2 \% \mathrm{C}_{8}-\mathrm{SiO}_{2}-\mathrm{SO}_{3} \mathrm{H}$ at different temperatures: (a) $30{ }^{\circ} \mathrm{C}$, (b) $50{ }^{\circ} \mathrm{C}$, (c) $60{ }^{\circ} \mathrm{C}$, (d) $70{ }^{\circ} \mathrm{C}$, (e) $80{ }^{\circ} \mathrm{C}$; Emulsions constructed by $2 \% \mathrm{C}_{18}-\mathrm{SiO}_{2}-\mathrm{SO}_{3} \mathrm{H}$ at different temperatures: (f) $30^{\circ} \mathrm{C}$, (g) $50{ }^{\circ} \mathrm{C}$, (h) $60^{\circ} \mathrm{C}$, (i) $70{ }^{\circ} \mathrm{C}$, (j) $80^{\circ} \mathrm{C}$. 
9. Effect of centrifugation speed on the emulsion volume

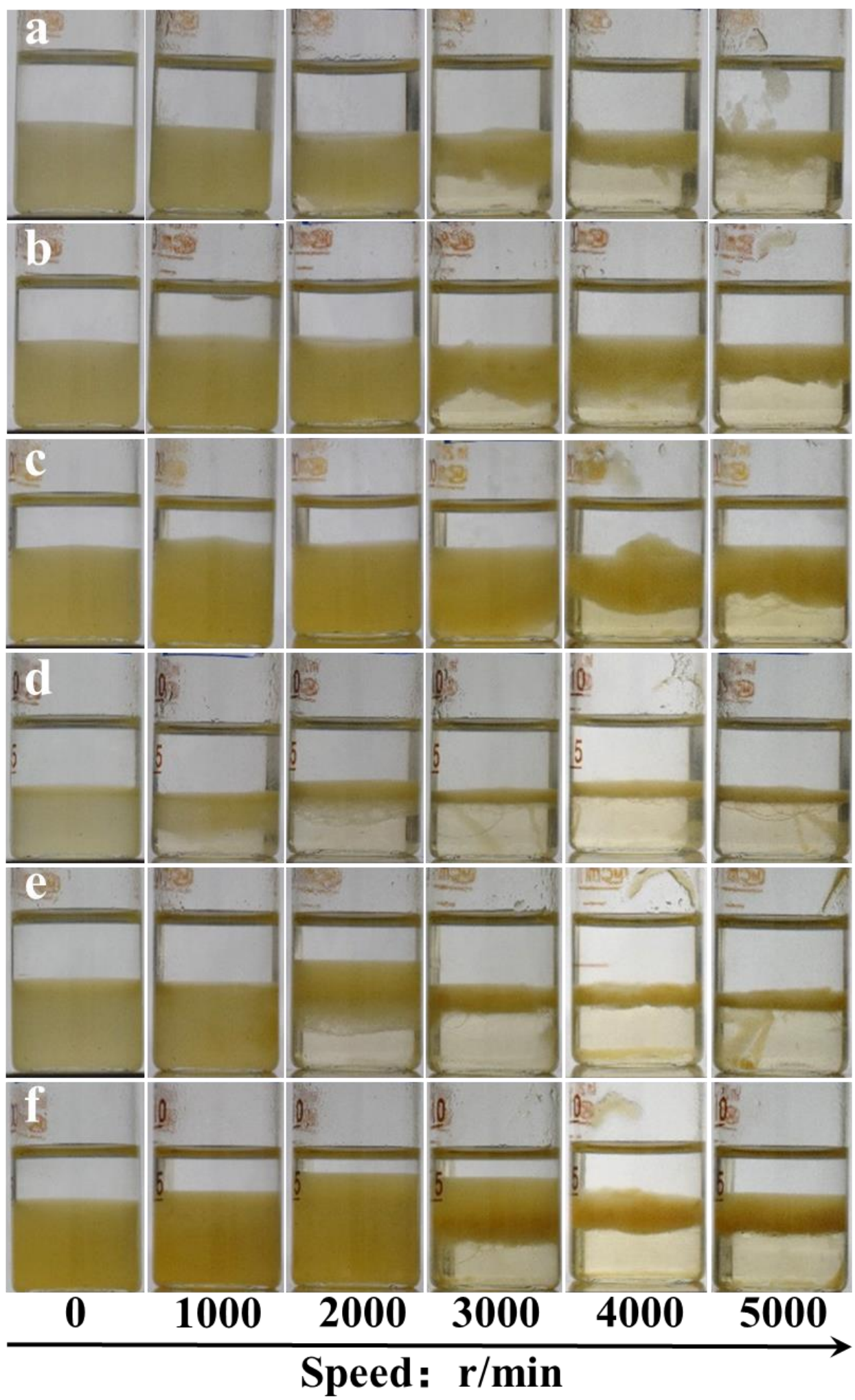

Figure S9. Emulsion volume at different centrifugal speeds for systems fabricated by $\mathrm{C}_{8^{-}}$and $\mathrm{C}_{18^{-}}$ $\mathrm{SiO}_{2}-\mathrm{SO}_{3} \mathrm{H}$. Mass percentage of $\mathrm{C}_{8}-\mathrm{SiO}_{2}-\mathrm{SO}_{3} \mathrm{H}$ : (a) $1 \%$, (b) $2 \%$, (c) $4 \%$; Mass percentage of $\mathrm{C}_{18^{-}}$ $\mathrm{SiO}_{2}-\mathrm{SO}_{3} \mathrm{H}:$ (d) $1 \%$, (e) $2 \%$, (f) $4 \%$. 
10. GC analysis of oligomerization products

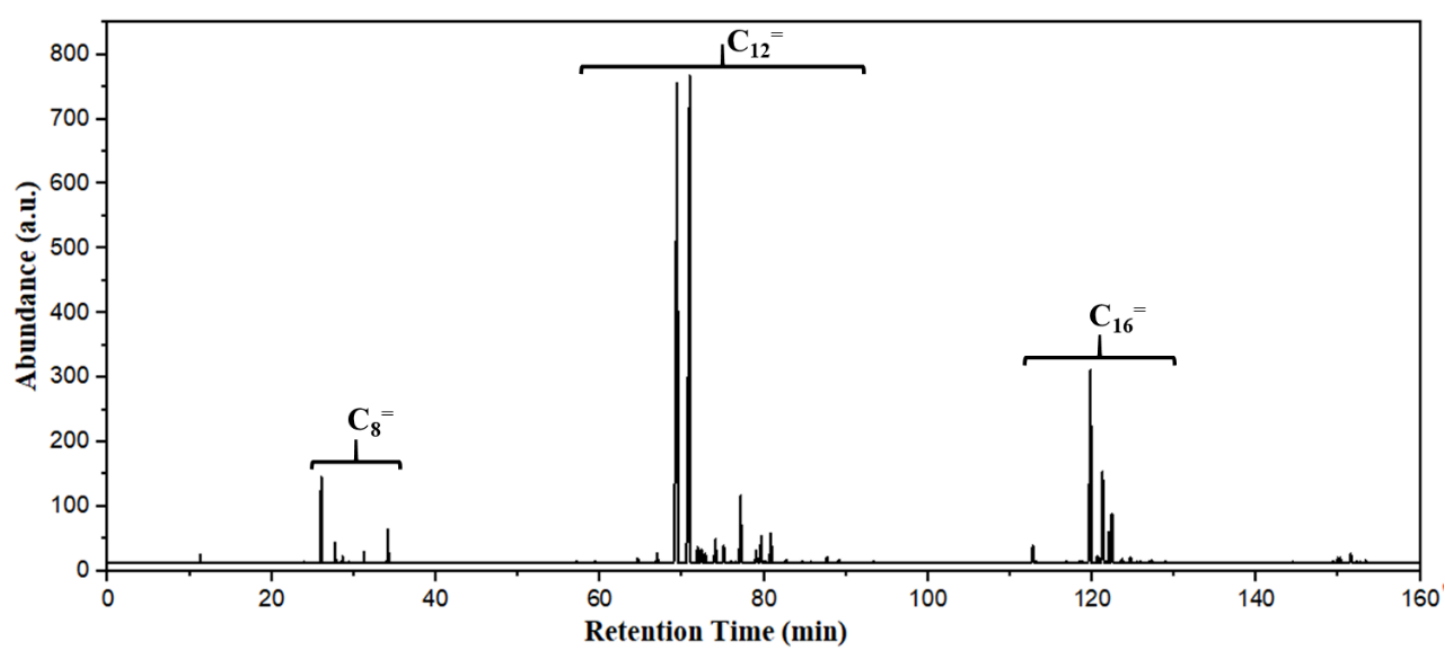

Figure S10. Typical GC chromatogram of reaction product in isobutene oligomerization. Reaction temperature: $40{ }^{\circ} \mathrm{C}$, time: $60 \mathrm{~min}$, pressure: $1.6 \mathrm{MPa}$, catalyst: $\mathrm{IL} / \mathrm{H}_{2} \mathrm{SO}_{4} / \mathrm{C}_{8}-\mathrm{SiO}_{2}-\mathrm{SO}_{3} \mathrm{H}$. 
11. Effect of IL concentration on production distribution
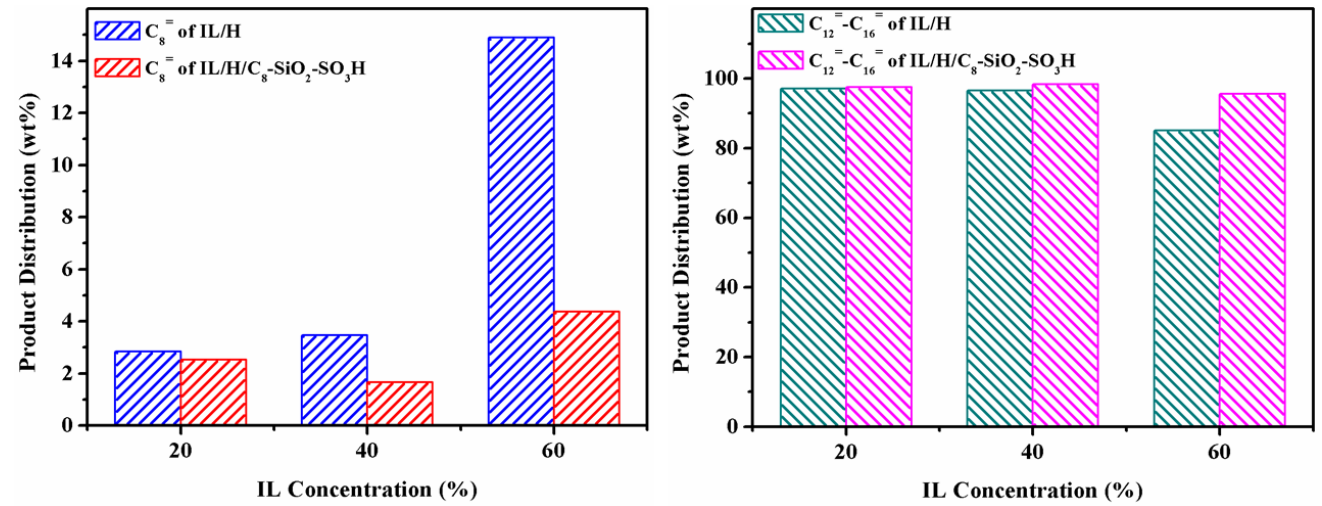

Figure S11. Product distribution (wt $\%)$ as a function of IL concentration for isobutene oligomerization catalyzed by ionic liquid/sulfuric acid in the absence/presence of $\mathrm{C}_{8}-\mathrm{SiO}_{2}-\mathrm{SO}_{3} \mathrm{H}$ (reaction temperature: $40{ }^{\circ} \mathrm{C}$, reaction time: $60 \mathrm{~min}$, pressure: $1.6 \mathrm{MPa}$ ). 


\section{Effect of reaction temperature/time on isobutene conversion}
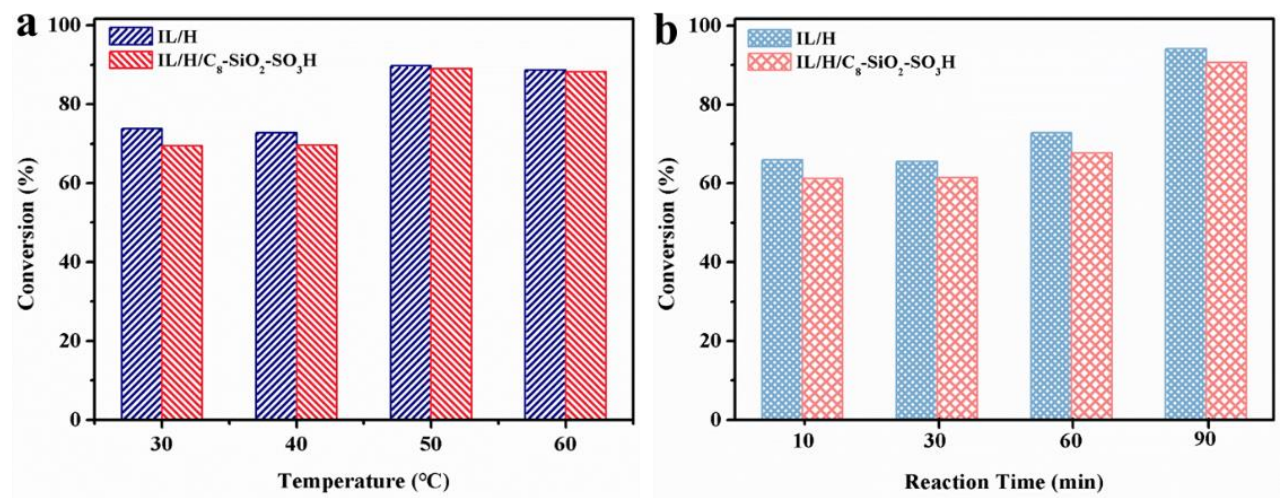

Figure S12. (a) Isobutene conversion as a function of temperature catalyzed by $60 \mathrm{wt} \%$ ionic liquid/sulfuric acid in the absence/presence of $\mathrm{C}_{8}-\mathrm{SiO}_{2}-\mathrm{SO}_{3} \mathrm{H}$ (reaction time: $60 \mathrm{~min}$, pressure: 1.6 MPa); (b) Isobutene conversion as a function of reaction time for isobutene oligomerization by 60 $\mathrm{wt} \%$ ionic liquid/sulfuric acid in the absence/presence of $\mathrm{C}_{8}-\mathrm{SiO}_{2}-\mathrm{SO}_{3} \mathrm{H}$ (temperature: $40{ }^{\circ} \mathrm{C}$, pressure: 1.6 $\mathrm{MPa})$. 